\title{
Lanthanide doping in metal halide perovskite nanocrystals: spectral shifting, quantum cutting and optoelectronic applications
}

\author{
Wasim J. Mir ${ }^{1}$, Tariq Sheikh (1)', Habibul Arfin', Zhiguo Xia ${ }^{2}$ and Angshuman Nag (1)
}

\begin{abstract}
Lanthanides have been widely explored as optically active dopants in inorganic crystal lattices, which are often insulating in nature. Doping trivalent lanthanide $\left(\mathrm{Ln}^{3+}\right)$ into traditional semiconductor nanocrystals, such as $\mathrm{CdSe}$, is challenging because of their tetrahedral coordination. Interestingly, $\mathrm{CsPbX}_{3}(X=\mathrm{Cl}, \mathrm{Br}, \mathrm{I})$ perovskite nanocrystals provide the octahedral coordination suitable for $\mathrm{Ln}^{3+}$ doping. Over the last two years, tremendous success has been achieved in doping $\mathrm{Ln}^{3+}$ into $\mathrm{CsPbX}_{3}$ nanocrystals, combining the excellent optoelectronic properties of the host with the $\mathrm{f}-\mathrm{f}$ electronic transitions of the dopants. For example, the efficient quantum cutting phenomenon in $\mathrm{Yb}^{3+}$-doped $\mathrm{CsPb}(\mathrm{Cl}, \mathrm{Br})_{3}$ nanocrystals yields a photoluminescence quantum yield close to $200 \%$. Other approaches of $\mathrm{Ln}^{3+}$ doping and codoping have enabled promising proof-of-principle demonstration of solid-state lighting and solar photovoltaics. In this perspective article, we highlight the salient features of the material design (including doping in $\mathrm{Pb}$-free perovskites), optical properties and potential optoelectronic applications of lanthanide-doped metal halide perovskite nanocrystals. While review articles on doping different metal ions into perovskite nanocrystals are present, the present review-type article is solely dedicated to lanthanide-doped metal halide perovskite nanocrystals.
\end{abstract}

\section{Introduction}

A variety of interesting optical properties and applications of inorganic materials depend on the presence of lanthanide ions $\left(\mathrm{Ln}^{2+} / \mathrm{Ln}^{3+}\right)$ doped into the crystal lattice. Generally, lanthanide ions, as optically active centers, provide energy levels within the band gap of the material, so they can give rise to the appearance of optical transitions at frequencies lower than that of the fundamental absorption. For example, $\mathrm{Ce}^{3+}$-doped $\mathrm{Y}_{3} \mathrm{Al}_{5} \mathrm{O}_{12}$ is a benchmark light emission material for commercial white light-emitting diodes (WLEDs) ${ }^{1}$. The $4 f-5 d$ transition of lanthanide ions represented by $\mathrm{Eu}^{2+}$ or $\mathrm{Ce}^{3+}$ is a parityallowed electric dipole transition, and thus, it is highly

Correspondence: Wasim J. Mir (wasimjeelani.mir@students.iiserpune.ac.in) or Zhiguo Xia (xiazg@scut.edu.cn) or Angshuman Nag (angshuman@iiserpune.ac.in) 'Department of Chemistry, Indian Institute of Science Education and Research (IISER), Pune 411008, India

${ }^{2}$ State Key Laboratory of Luminescent Materials and Devices and Institute of Optical Communication Materials, South China University of Technology, Guangzhou 510641, China efficient. However, typical $\mathrm{Ln}^{3+}$ ions, except for $\mathrm{Ce}^{3+}$, exhibit $4 f-4 f$ forbidden transitions with well-defined energy levels that are nearly invariable in different hosts due to the shielding of $4 f$ orbitals $^{2,3}$. Thus, the photoluminescence (PL) arising from the $f-f$ transition exhibits a long lifetime $(\sim \mathrm{ms})$, along with a poor light absorption coefficient $\left(\sim 1-10 \mathrm{M}^{-1} \mathrm{~cm}^{-1}\right)^{4}$. Therefore, organic dyes and complexes have been used as light absorbing sensitizers to nonradiatively excite the $f$ electrons of $\mathrm{Ln}^{3+}$ ions, and light is emitted via the subsequent de-excitation of the $f$ electrons ${ }^{5}$. To boost the PL quantum yield (QY) of $\mathrm{Ln}^{3+}$ ions, $\mathrm{Ln}^{3+}$ ions have been doped into crystalline sensitizers, shielding the excited $\mathrm{f}$ electrons from unwanted nonradiative decay channels.

All-inorganic, metal-halide perovskite $\mathrm{CsPbX}_{3}(\mathrm{X}=\mathrm{Cl}$, $\mathrm{Br}, \mathrm{I})$ nanocrystals (NCs) have recently been the subject of intense research ${ }^{6-13}$. Morphology modification, size control and compositional alloying play important roles in PL tuning and optoelectronic applications, such as LEDs, 
lasers, displays, solar cells, and photodetectors. Moreover, the incorporation of impurity ions or doping is a promising method for controlling the electronic and optical properties and the structural stability of halide perovskite $\mathrm{NCs}^{14-19}$. Lanthanide ions with unique optical properties have been successfully doped into $\mathrm{CsPbX}_{3} \mathrm{NCs}^{20-23}$. These materials demonstrate the rich, efficient, and inherently narrow $4 f-4 f$ emission features of the lanthanides sensitized by the perovskite NCs. Except for the normal spectral shifting behavior, $\mathrm{Yb}^{3+}$-doped $\mathrm{CsPbCl}_{3}$ NCs particularly show excellent near-infrared (NIR) PL with QY approaching 200\% because of a rarely observed phenomenon, namely, quantum cutting. The combination of efficient quantum cutting and the strong absorption cross-section of $\mathrm{CsPCl}_{3}$ for the UV-blue region of the solar spectrum lead to novel strategies for solar light harvesting, such as (i) depositing a quantum cutting layer on a Si solar cell to improve its efficiency and (ii) utilizing luminescent solar concentrators.

In this perspective article, we discuss the exciting research developments in $\mathrm{Ln}^{3+}$-doped metal halide perovskite NCs in the following subsections: (i) lanthanide doping in octahedral (perovskite) semiconductor NCs, (ii) luminescence via spectral shifting from lanthanide-doped $\mathrm{CsPbCl}_{3}$ perovskite NCs, (iii) quantum cutting and band gap tuning, (iv) optoelectronic applications, (v) prospects of lanthanide doping in $\mathrm{Pb}$-free perovskites, and (v) conclusions and future outlook.

\section{Lanthanide doping in octahedral (perovskite) semiconductor NCs}

Figure 1 depicts $\mathrm{Ln}^{3+}$ doping in widely studied crystal lattices from insulators to semiconductors. $\mathrm{Ln}^{3+}$ doping in oxide and fluoride lattices, such as $\mathrm{Y}_{3} \mathrm{Al}_{5} \mathrm{O}_{12}, \mathrm{NaYF}_{4}$, and $\mathrm{NaGdF}_{4}$, has been successfully realized due to the higher coordination (coordination number, $\mathrm{CN}=8$ or 9) environment possible for $\mathrm{Ln}^{3+}$ dopants ${ }^{24-26}$. However, a drawback of such host materials is their wide band gap, yielding both poor visible light absorption and poor charge transport. Therefore, for visible light optoelectronic applications, including solar light harvesting and LEDs, efforts have been made to dope $\mathrm{Ln}^{3+}$ into the lattice of semiconductors. However, $\mathrm{Ln}^{3+}$ doping in semiconductors has remained challenging because most semiconductors, such as $\mathrm{CdSe}, \mathrm{CdS}, \mathrm{Si}$, GaAs, and InP, offer a tetrahedral $(\mathrm{CN}=4)$ coordination environment for $\mathrm{Ln}^{3+}$ dopants, whereas $\mathrm{Ln}^{3+}$ ions prefer sites with $\mathrm{CN} \geq 6^{27,28}$. It is noteworthy that lead halide perovskites are a rare class of semiconductors that possess octahedral coordination $(\mathrm{CN}=6)$ for $\mathrm{Pb}$ (B-site cation); therefore, they provide an opportunity to dope lanthanide ions into optoelectronically active semiconductors. $\mathrm{CsPbX}_{3} \mathrm{NCs}$ exhibiting strong visible light absorption and intense emission arising from their

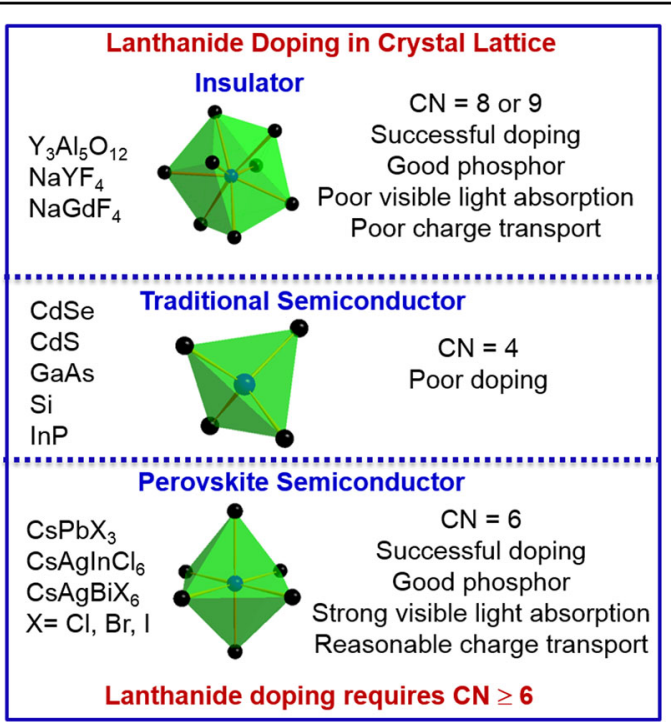

Fig. 1 Lanthanide doping in crystal lattices beyond insulators. Schematics showing the coordination environment provided to $\mathrm{Ln}^{3+}$ by different host lattices. $\mathrm{Ln}^{3+}$ doping preferentially occurs in lattices with coordination number $(\mathrm{CN}) \geq 6$. Therefore, metal halide

perovskites with $\mathrm{CN}=6$ exhibiting good optoelectronic properties are ideal semiconductor host NCs for $\mathrm{Ln}^{3+}$ doping.

excitonic (band gap) transitions, along with reasonable charge transport properties, are therefore ideal hosts for $\mathrm{Ln}^{3+}$ ion doping.

\section{Luminescence via spectral shifting from lanthanide-doped $\mathrm{CsPbCl}_{3}$ perovskite NCs}

The first manuscript on $\mathrm{Ln}^{3+}\left(\mathrm{Yb}^{3+}, \mathrm{Ce}^{3+}, \mathrm{Er}^{3+}\right)$ doping in $\mathrm{CsPCCl}_{3}$ and mixed halide $\mathrm{CsPb}(\mathrm{Cl}, \mathrm{Br})_{3}$ perovskite NCs was reported in 2017 after the seminal work of Song and coworkers $^{20}$. The same group expanded the scope of optical properties by doping a large number of $\mathrm{Ln}^{3+}$ ions into $\mathrm{CsPbCl}_{3} \mathrm{NCs}$ (Fig. 2) 2 $^{21}$. Typically, halide salts of $\mathrm{Ln}^{3+}$ are widely used precursors to dope perovskite NCs into organic solvents at high temperatures $\left(200-240{ }^{\circ} \mathrm{C}\right)$ through hot injection synthesis ${ }^{20,21}$. Fine control of the $\mathrm{Ln}^{3+}$ dopant in $\mathrm{CsPbCl}_{3} \mathrm{NCs}$ has been achieved by the choice of $\mathrm{Ln}^{3+}$ precursors. Gamelin and coworkers found that the acetate salt of $\mathrm{Yb}^{3+}\left(\mathrm{Yb}\left(\mathrm{CH}_{3} \mathrm{COO}\right)_{3} \cdot \mathrm{xH}_{2} \mathrm{O}\right)$ could achieve higher solubility in organic solvents at high temperature compared to the $\mathrm{YbCl}_{3} \cdot 6 \mathrm{H}_{2} \mathrm{O}$ precursor ${ }^{22}$. Likewise, acetate or nitrate precursors of $\mathrm{Ln}^{3+}$ have been used to dope lead-free metal halide double perovskite $\mathrm{NCs}^{29,30}$. However, easy and flexible $\mathrm{Ln}^{3+}$ doping in narrower band gap hosts, such as $\mathrm{CsPbBr}_{3}$ and $\mathrm{CsPbI}_{3}$ $\mathrm{NCs}$, is challenging. Very few reports were able to achieve $\mathrm{Ln}^{3+}$ doping in $\mathrm{CsPBrr}_{3} \mathrm{NCs}$ by employing a direct synthesis using halide precursors of $\mathrm{Ln}^{3+31,32}$. This challenge of doping narrower band gap hosts could alternatively be handled by postsynthesis strategies, as 


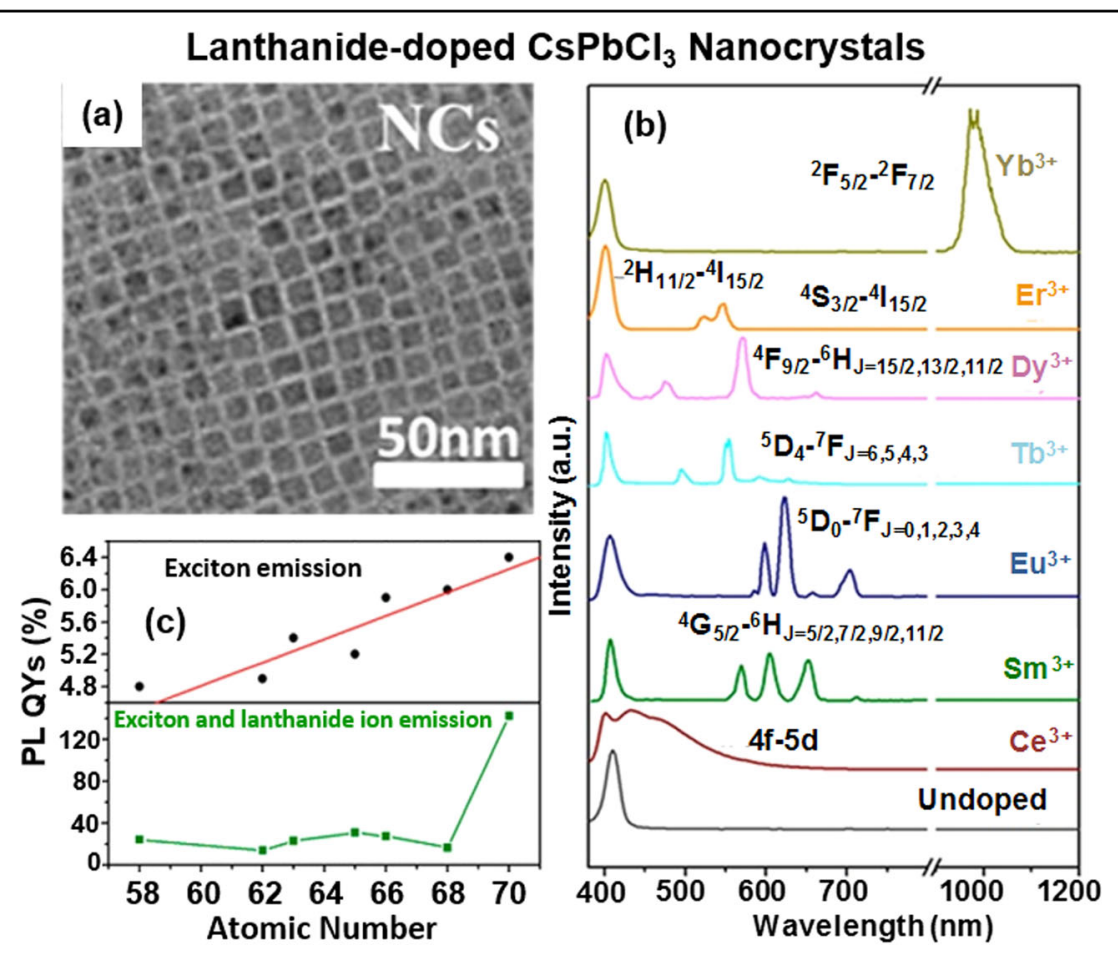

Fig. 2 Luminescence from various lanthanide-doped colloidal $\mathrm{CsPbCl}_{3}$ perovskite $\mathbf{N C s}$. a Transmission electron microscopy image of $\mathrm{CsPbCl}_{3}$ perovskite NCs. b PL spectra of undoped and 7.2\% $\mathrm{Ce}^{3+}, 7.3 \% \mathrm{Sm}^{3+}, 7.9 \% \mathrm{Eu}^{3+}, 7.6 \% \mathrm{~Tb}^{3+}, 7.4 \% \mathrm{Dy}^{3+}, 7.8 \% \mathrm{Er}^{3+}$, and 9.1\% $\mathrm{Yb}^{3+}$-doped $\mathrm{CsPbCl}_{3}$ perovskite NCs. c PL QYs of excitonic emission (red line in upper panel) and excitonic along with lanthanide dopant emission (green line in lower panel) in various $\mathrm{Ln}^{3+}$-doped $\mathrm{CsPbCl}_{3}$ perovskite NCs. The figures are adapted from ref. ${ }^{21}$ with Copyright $\odot$ 2017, American Chemical Society.

discussed later in the quantum cutting and band gap tuning section.

The PL spectra in Fig. 2b show that the undoped sample exhibits only excitonic emission, but all the doped samples show multiple emission peaks arising from both excitonic and dopant emissions. None of these $\mathrm{Ln}^{3+}$ dopants absorbs a measurable amount of light, and therefore, the absorption of light is dominated by the excitonic (or band gap) transition of the host $\mathrm{CsPbCl}_{3}$ at wavelengths $<420 \mathrm{~nm}^{21}$. Therefore, the $\mathrm{Ln}^{3+}$ emissions are sensitized by the host.

Figure 2c shows the absolute PL QYs of the excitonic and total (excitonic + dopant) emission for various $\mathrm{Ln}^{3+}$-doped $\mathrm{CsPbCl}_{3} \mathrm{NCs}$. The PL QY of $\mathrm{Yb}^{3+}$ emission is by far the highest. Surprisingly, the first three reports of $\mathrm{Yb}^{3+}$ doping in $\mathrm{CsPbCl}_{3}$ or $\mathrm{CsPb}(\mathrm{Cl}, \mathrm{Br})_{3} \mathrm{NCs}$ reported a very unusual PL QY exceeding the ideal value $100 \%{ }^{20-22}$. A long PL lifetime $>2 \mathrm{~ms}$ was reported for the Laporte forbidden NIR $\mathrm{Yb}^{3+}$ emission, suggesting incorporation of the dopants into the host lattice ${ }^{22}$. Local structure studies also confirm that $\mathrm{Yb}^{3+}$ occupies the octahedral $\mathrm{Pb}^{2+}$ site of $\mathrm{CsPbCl}_{3} \mathrm{NCs}^{33}$. Gamelin and coworkers reported an $\sim 190 \%$ PL QY from not only NCs but also bulk-like thin films of $\mathrm{Yb}^{3+}$-doped $\mathrm{CsPbCl}_{3}{ }^{34}$. This extraordinarily high $\mathrm{PL} \mathrm{QY}$ for $\mathrm{Yb}^{3+}$ emission received significant attention from researchers for both fundamental studies and possible future applications. Consequently, both the prior literature on lanthanide-doped perovskite $\mathrm{NCs}$ and our present perspective are dominated by the studies on $\mathrm{Yb}^{3+}$ doping.

\section{Quantum cutting and band gap tuning}

In the previous subsection, we discussed the PL QY of $\mathrm{Yb}^{3+}$-doped $\mathrm{CsPbCl}_{3} \mathrm{NCs}$ approaching $\sim 200 \%$. Figure 3a shows that the absorption onset $(420 \mathrm{~nm}, 2.95 \mathrm{eV})$ is more than twice the $\mathrm{Yb}^{3+}$ emission energy $(992 \mathrm{~nm}, 1.25 \mathrm{eV})^{22}$. Therefore, in principle, it is possible that one absorbed photon of energy $\geq 2.95 \mathrm{eV}$ can yield two emitted photons of $1.25 \mathrm{eV}$ energy, following a phenomenon known as quantum cutting (Fig. 3a). Moreover, the PL QY of NIR $\mathrm{Yb}^{3+}$ emission in $\mathrm{Yb}^{3+}$-doped $\mathrm{CsPbCl}_{3} \mathrm{NCs}$ shows a fluence-dependent nature under varying excitation power at $\lambda_{\text {exc }}=380 \mathrm{~nm}^{22}$. At lower excitation power, the PL QY of the $\mathrm{Yb}^{3+}$ emission increases and reaches close to $200 \%$, showing a very efficient quantum cutting phenomenon. This high PL QY at low excitation power is possible due to the high absorption coefficient of the $\mathrm{CsPCl}_{3} \mathrm{NC}$ host, which directly transfers excitonic energy to $\mathrm{Yb}^{3+}$ ions upon photoexcitation. Unlike in conventional quantum cutting $^{20,35}$, a high-energy photon absorbed by the host is directly converted to two low-energy photons without the requirement of two different lanthanide ions. 


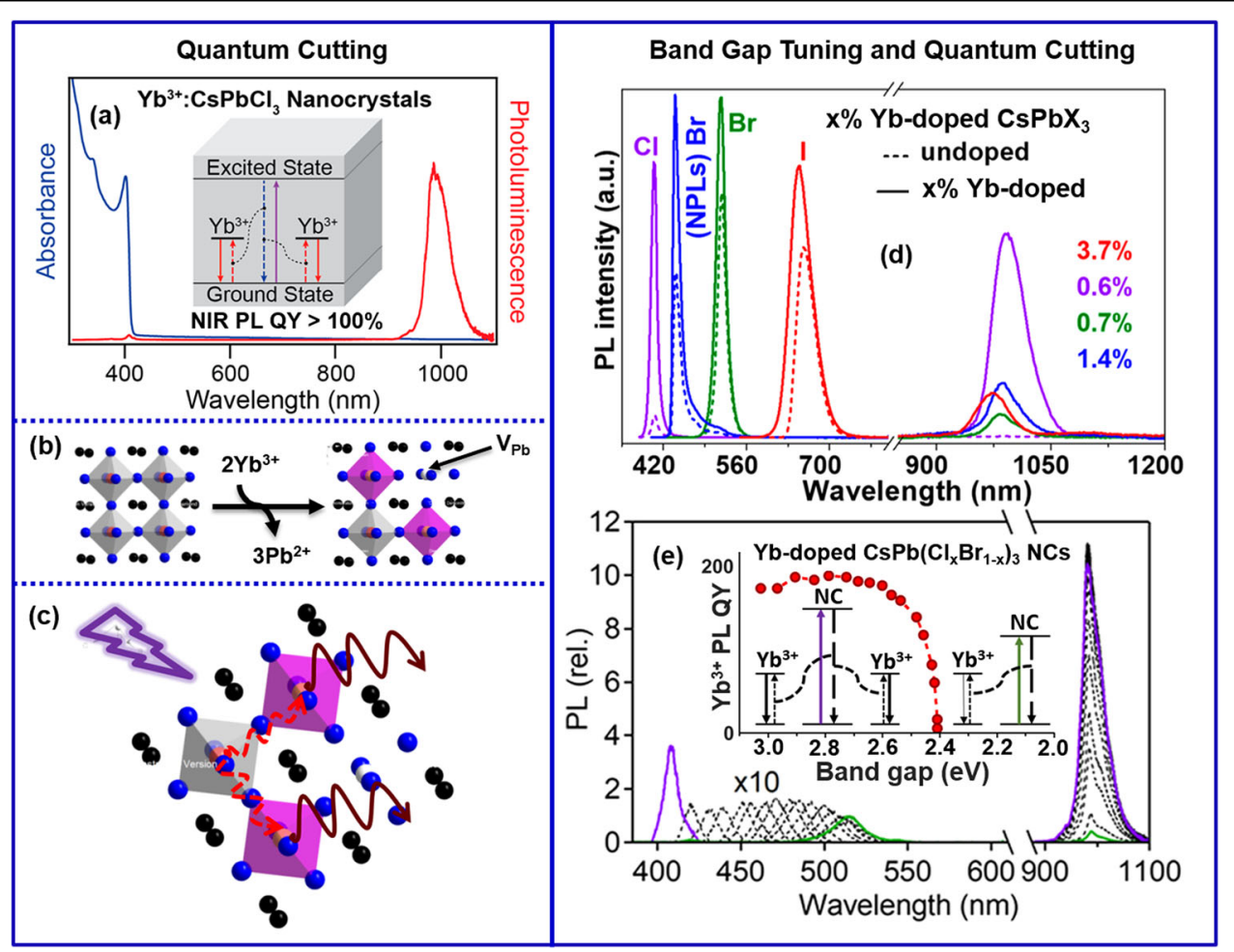

Fig. 3 Quantum cutting and band gap tuning. a Optical absorption and PL spectra of $\mathrm{Yb}^{3+}$-doped $\mathrm{CsPbCl}_{3}$ perovskite NCs. The schematic in the inset shows the quantum cutting of one high-energy absorbed photon into two low-energy photons in $\mathrm{Yb}^{3+}$ emission, giving rise to $\mathrm{PL} \mathrm{QY}>100 \%$. Figure a is adopted from ref. ${ }^{22}$ with Copyright $\odot$ 2018, American Chemical Society. b Atomic model in which $2 \mathrm{Yb}^{3+}$ ions replace $3 \mathrm{~Pb}^{2+}$ ions in the crystal lattice of $\mathrm{CsPbCl}_{3}$, leading to the formation of the right angled charge neutral $\mathrm{Yb}^{3+}-\mathrm{VPb}-\mathrm{Yb}^{3+}$ defect complex. Black spheres represent $\mathrm{Cs}$, white sphere represents $\mathrm{Pb}$ vacancies $\left(\mathrm{V}_{\mathrm{Pb}}\right)$, gray colored octahedra correspond to $\mathrm{PbCl}_{6}$, and pink colored octahedra correspond to $\mathrm{YbCl}_{6}$. c Nonradiative excitonic energy transfer from $\mathrm{PbCl}_{6}$ octahedra to the two nearest $\mathrm{Yb}^{3+}$ dopants in a concerted manner. $\mathbf{d} \mathrm{PL}$ spectra of undoped and $\mathrm{x} \% \mathrm{Yb}^{3+}$-doped $\mathrm{CsPbX}_{3}\left(\mathrm{X}=\mathrm{Cl}, \mathrm{Br}\right.$, I) perovskite NCs along with $\mathrm{CsPbBr}_{3}$ perovskite nanoplatelets (NPLs, blue spectra) obtained though postsynthesis

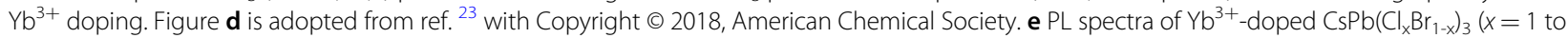
0) NCs obtained through postsynthesis anion exchange of $\mathrm{Yb}^{3+}$-doped $\mathrm{CsPbCl}_{3}$ perovskite NCs. The schematic in the inset shows the $\mathrm{PL} \mathrm{QY}$ of $\mathrm{Yb}^{3+}$ emission at $992 \mathrm{~nm}$ as a function of the optical band gap of $\mathrm{CsPb}\left(\mathrm{Cl}_{x} \mathrm{Br}_{1-x}\right)_{3}$ perovskite NCs. Figure e is adapted from ref. ${ }^{37}$ with Copyright $\odot 2019$, American Chemical Society.

Gamelin and coworker reported an efficient quantum cutting process at the picosecond scale ${ }^{22}$. To maintain charge neutrality, the incorporation of two $\mathrm{Yb}^{3+}$ ions will lead to the removal of three $\mathrm{Pb}^{2+}$ ions, creating $\mathrm{Pb}^{2+}$ vacancies $\left(\mathrm{V}_{\mathrm{Pb}}\right)$, thereby forming a $\mathrm{Yb}-\mathrm{Cl}-\mathrm{V}_{\mathrm{Pb}}-\mathrm{Cl}-\mathrm{Yb}$ defect complex (Fig. 3b). It was suggested that this defect forms a shallow state below the conduction band minimum, facilitating picosecond nonradiative energy transfer from the photoexcited host $\mathrm{NC}$ to two $\mathrm{Yb}^{3+}$ ions simultaneously, yielding quantum cutting ${ }^{22}$. Later, theoretical studies extended the mechanistic insight ${ }^{36}$. They suggested that the two $\mathrm{Yb}^{3+}$ dopants are excited in a concerted manner through nonradiative energy transfer from the $\mathrm{PbCl}_{6}$ octahedra closest to the two $\mathrm{Yb}^{3+}$ dopants (see Fig. $3 c)^{36}$.

All these studies were performed with $\mathrm{Yb}^{3+}$ doping in $\mathrm{CsPCl}_{3}$ or $\mathrm{CsPb}(\mathrm{Cl} / \mathrm{Br})_{3}$ perovskite NCs with a band gap $>2.88 \mathrm{eV}(430 \mathrm{~nm})$. Doping $\mathrm{Yb}^{3+}$ into narrower band gap perovskites, such as $\mathrm{CsPbBr}_{3}$ and $\mathrm{CsPb}_{3} \mathrm{NCs}$, was found to be challenging. Such tuning of the band gap of the host NCs is interesting for both a fundamental understanding of the role of the band gap in quantum cutting and possible applications requiring more visible light absorption. To address this challenge of band gap tuning in $\mathrm{Yb}^{3+}$-doped $\mathrm{CsPbX}_{3} \mathrm{NCs}$, two strategies are adopted: (i) postsynthesis doping of $\mathrm{Yb}^{3+}$ into preformed NCs with the desired band gap $^{23}$ and (ii) anion exchange of $\mathrm{Yb}^{3+}$-doped $\mathrm{CsPbCl}_{3}$ perovskite $\mathrm{NCs}^{37}$. The postsynthesis doping of $\mathrm{Yb}^{3+}$ into all compositions of $\mathrm{CsPbX}_{3}(\mathrm{X}=\mathrm{Cl}, \mathrm{Br}, \mathrm{I}) \mathrm{NCs}$ (also into $\mathrm{CsPbBr}_{3}$ nanoplatelets (NPLs)) yielded NIR $\mathrm{Yb}^{3+}$ emission (see Fig. 3d) ${ }^{23}$. However, the relative intensity of the NIR $\mathrm{Yb}^{3+}$ emission is significantly decreased for $\mathrm{CsPbBr}_{3}$ and $\mathrm{CsPbI}_{3} \mathrm{NCs}$. In the anion exchange approach, the PL QY of the NIR $\mathrm{Yb}^{3+}$ emission sharply dips for band gaps smaller than $2.5 \mathrm{eV}$, as shown in Fig. 3e and its inset ${ }^{37}$. The band gap of $2.5 \mathrm{eV}$ is thus termed the threshold value above which the quantum cutting phenomenon is realized in $\mathrm{Yb}^{3+}$-doped $\mathrm{CsPb}\left(\mathrm{Cl}_{1-\mathrm{x}} \mathrm{Br}_{\mathrm{x}}\right)_{3} \mathrm{NCs}$. 


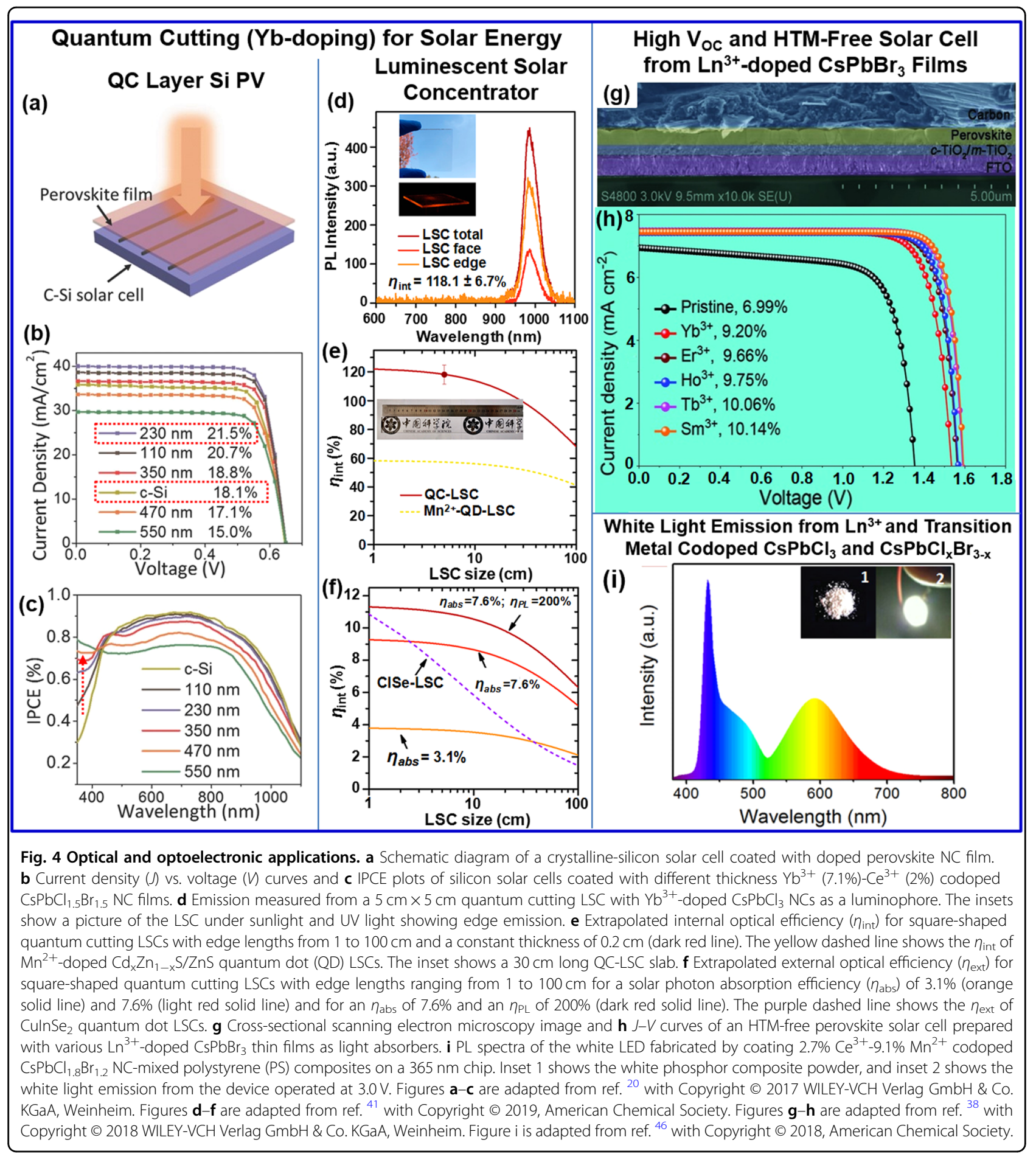

\section{Optoelectronic applications}

The light emitted by $\mathrm{Yb}^{3+}$ at $\sim 990 \mathrm{~nm}$ is suitable for absorption by a commercial Si solar cell with reasonably good incident photon-to-current conversion efficiency (IPCE). Consequently, efforts have been made to improve the power conversion efficiencies (PCEs) of Si solar cells via two mechanisms: (i) using a quantum cutting layer on a Si solar cell (Fig. 4a-c) and (ii) using luminescent solar concentrators (LSCs) (Fig. 4d-f) to build integrated photovoltaics. In a different direction, lanthanide doping was found to increase the grain size of $\mathrm{CsPbBr}_{3}$ microcrystals in a film, thereby increasing the carrier lifetime and efficiencies of perovskite solar cells (Fig. $4 \mathrm{~g}, \mathrm{~h})^{38}$. In addition, the different luminescence colors arising from 
different lanthanide dopants are being explored for lightemitting applications, including white LEDs (Fig. 4i). In this subsection, the progress in and challenges for these possible applications will be discussed.

\section{Quantum cutting (QC) layer on a Si solar cell}

Zhou et al. improved the PCE of a Si solar cell from $18.1 \%$ to $21.5 \%$ simply by coating the solar cell with a $\mathrm{Yb}^{3+}(7.1 \%)-\mathrm{Ce}^{3+}(2 \%)$ codoped $\mathrm{CsPbCl}_{1.5} \mathrm{Br}_{1.5} \mathrm{NC}$ layer (Fig. 4a, b) ${ }^{20}$. As shown in Fig. 4c, the IPCE of the Si solar cell significantly decreases for the solar spectrum below $450 \mathrm{~nm}$. The idea here is that the layer of $\mathrm{Yb}^{3+}$-doped (or $\mathrm{Yb}^{3+}-\mathrm{Ce}^{3+}$ codoped) $\mathrm{CsPbX}_{3} \mathrm{NCs}$ absorbs this part $(<450 \mathrm{~nm})$ of the solar light and converts it to $\sim 990 \mathrm{~nm}$ $\mathrm{Yb}^{3+}$ emission (PL QY > 100\%), which is then reabsorbed by the Si solar cell. The quantum cutting layer increases the IPCE of the Si solar cell in the $350-450 \mathrm{~nm}$ region, improving the solar cell efficiency. The thickness of the quantum cutting NC layer needs to be optimized to $\sim 230 \mathrm{~nm}$ so that the layer sufficiently absorbs solar light below $<450 \mathrm{~nm}$ but remains transparent to $450-1000 \mathrm{~nm}$ light, which is directly absorbed by the Si solar cell with high IPCE.

Another important point is that the absorbed ultraviolet-blue light possesses energy much higher than the band gap of the solar cell materials, including Si. This excess energy is lost as heat during relaxation of the hot carriers to the band edges. Such thermalization losses constitute a significant part of the total losses causing the Shockley-Queisser thermodynamic limit of the PCE for single-junction $\mathrm{Si}$ solar cells of $31 \%^{39}$. Converting UVblue light to NIR light using a quantum cutting layer has the potential to reduce the thermalization losses, thereby achieving a theoretical efficiency of a single-junction solar cell beyond the Shockley-Queisser limit, similar to the case of tandem solar cells ${ }^{40}$. More theoretical and experimental works are required to verify the efficacy of $\mathrm{Yb}^{3+}$-doped quantum cutting $\mathrm{NC}$ layers in reducing the thermalization losses.

\section{Luminescent solar concentrators (LSCs)}

LSCs absorb incident solar light, and then, the emitted lower energy light is waveguided to the edges of the device by total internal reflection. A photovoltaic device attached to the edge of the LSC absorbs the waveguided light and converts it into usable power. The internal optical efficiency $\left(\eta_{\text {int }}\right)$ of an LSC is the ratio of edge-emitted photons to absorbed solar photons. Therefore, to achieve high $\eta_{\text {int }}$, we need both high PL QY and minimal reabsorption of the emitted light by the medium of the LSC such that the emitted light can travel to the edges of the LSC without any loss. $\mathrm{Yb}^{3+}$-doped $\mathrm{CsPbX}_{3} \mathrm{NCs}$ fulfill both criteria because of the quantum cutting that provides $>100 \%$ PL QY and the large redshift between absorption and $\mathrm{Yb}^{3+}$ emission (see Fig. 3a). Wu and coworker reported a very high $\eta_{\text {int }}(118.1 \%)$ using $\mathrm{Yb}^{3+}$-doped $\mathrm{CsPbCl}_{3} \mathrm{NCs}$ as a luminophore in a $25 \mathrm{~cm}^{2}$ sized LSC (Fig. $4 \mathrm{~d})^{41}$. The upper inset of Fig. 4d shows that the $\mathrm{Yb}^{3+}$-doped LSC is largely transparent to visible light, suggesting that such LSCs can be used in the glass window material for a building, whereas the lower inset shows that the luminescence generated in the LSC travel to its edges. Extrapolation of the data (Fig. 4e) shows the possibility of high $\eta_{\text {int }}$ using $\mathrm{Yb}^{3+}$-doped $\mathrm{CsPbCl}_{3} \mathrm{NCs}$ in a large-size LSC. Interestingly, the $\eta_{\text {int }}$ of the $\mathrm{Yb}^{3+}$-doped sample is approximately 2-fold higher than that of the $\mathrm{Mn}^{2+}$-doped quantum dot $\mathrm{LSC}^{42}$. The external optical efficiency $\left(\eta_{\text {ext }}\right)$ of an LSC also depends on the solar photon absorption efficiency $\left(\eta_{\mathrm{abs}}\right)$ of the luminophore. The wide band gap of $\mathrm{CsPbCl}_{3} \mathrm{NCs}$ reduces their solar absorption capability to only $3.1 \% \eta_{\mathrm{abs}}$, leading to an $\eta_{\text {ext }}$ of $3.7 \%$ from a $5 \mathrm{~cm}^{2}$ LSC. This $\eta_{\text {ext }}$ is not high compared with previous quantum $\mathrm{LSCs}^{41,42}$. $\mathrm{Yb}^{3+}$ doping in narrower band gap $\mathrm{CsPCl}_{\mathrm{x}} \mathrm{Br}_{3-\mathrm{x}} \mathrm{NCs}$ with a higher $\eta_{\mathrm{abs}}$ of $7.6 \%$ shows a much-improved $\eta_{\text {ext }}$ of $9.0 \%$ for a $5 \mathrm{~cm}^{2} \mathrm{LSC}$ (Fig. 4f $)^{41}$. However, this narrowing of the host band gap will reduce the visible light transparency of LSCs.

\section{Perovskite solar cells}

In a different direction from quantum cutting for improving the efficiency of $\mathrm{Si}$ solar cells, lanthanide doping has been reported to increase the efficiency and stability of perovskite solar cells ${ }^{38,43-45} \cdot \mathrm{Ln}^{3+}$ doping has been reported to reduce lattice and surface defects of both $\mathrm{NCs}$ and bulk-like perovskite thin films ${ }^{32,38}$. Figure $4 \mathrm{~g}, \mathrm{~h}$ shows that the solar cell performance of $\mathrm{CsPbBr}_{3}$ thin films significantly improves with various lanthanide doping. For example, Sm doping increases the PCE from 6.99 to $10.14 \%$ using a device geometry that does not require hole-transporting materials (HTMs) ${ }^{38}$. More importantly, the open-circuit voltage increases from $1.35 \mathrm{~V}$ for the pristine sample to $1.59 \mathrm{~V}$ upon doping of $\mathrm{Sm}^{3+}$ into $\mathrm{CsPbBr}_{3}$ microcrystals ${ }^{38}$. Likewise, the open-circuit voltage increases for other $\mathrm{Ln}^{3+}$-doped $\mathrm{CsPbBr}_{3}$ polycrystalline films compared to the undoped $\mathrm{CsPBrr}_{3}$ film ${ }^{38}$. The open-circuit voltage of $1.59 \mathrm{~V}$ is indeed very high compared to most other solar cell materials.

\section{White light emission}

Good-quality white light generation requires the simultaneous emission of red, green and blue colors in appropriate proportions. However, the simultaneous generation of these three colors with high efficiency and without self-absorption (which may change the color ratio) is difficult. Doping allows the generation of multiple emissions and is free from self-absorption. Song and coworkers reported white light emission from lanthanide $\left(2.7 \% \mathrm{Ce}^{3+}\right)$ and transition metal $\left(9.1 \% \mathrm{Mn}^{2+}\right)$ codoped 
CsPbCl ${ }_{1.8} \mathrm{Br}_{1.2}$ NCs with a high PL QY of $72 \%$ (Fig. $\left.4 \mathrm{i}\right)^{46}$. Optically pumped white light LEDs of these codoped NCs exhibit a luminous efficiency of $51 \mathrm{~lm} / \mathrm{W}$ and a color rendering index of 89 after excitation with a $365 \mathrm{~nm} \mathrm{GaN}$ LED chip. Typically, near UV light pumped white LEDs can generate a high color rendering index of 94 , but at the cost of a poor luminous efficiency of $\sim 23 \mathrm{~lm} / \mathrm{W}$, for rare earth ion doping in oxide lattices ${ }^{47}$. Interestingly, codoped perovskite NCs under near UV light excitation result in a reasonably high luminous efficiency while maintaining a high color rendering index.

\section{Prospect of lanthanide doping in $\mathrm{Pb}$-free perovskites}

$\mathrm{Pb}$-free metal halide perovskites are being explored both to address fundamental curiosity and to overcome the toxicity and instability issues of $\mathrm{Pb}$-halide perovskite $\mathrm{NCs}^{48-50}$. A popular type of $\mathrm{Pb}$-free halide perovskite is double perovskites such as $\mathrm{Cs}_{2} \mathrm{AgInCl}_{6}$ (see Fig. 5a), where two $\mathrm{Pb}^{2+}$ ions are replaced by one monovalent cation (e.g., $\mathrm{Ag}^{+}, \mathrm{Na}^{+}$, or $\mathrm{Cu}^{+}$) and one trivalent cation (e.g., $\mathrm{In}^{3+}, \mathrm{Bi}^{3+}$, or $\left.\mathrm{Sb}^{3+}\right)^{51,52}$. These double perovskites are stable but possess a wide and/or forbidden band gap, hindering their optoelectronic applications. Doping of metal ions, such as $\mathrm{Mn}^{2+53-55}, \mathrm{Bi}^{3+56-58}$, and $\mathrm{Ln}^{3+29,30}$, is currently being explored, both into microcrystals and $\mathrm{NCs}$, to impart optical and optoelectronic properties in the visible and infrared region. $\mathrm{Yb}^{3+}$ doping in $\mathrm{Cs}_{2} \mathrm{~A}$ $\mathrm{gInCl}_{6}$ introduces NIR emission for both microcrystals (Fig. 5b, c) and colloidal NCs (Fig. 5d, e), qualitatively similar to $\mathrm{Yb}^{3+}$-doped $\mathrm{CsPbX}_{3} \mathrm{NCs}^{30}$. Kim and coworker doped both $\mathrm{Yb}^{3+}$ and $\mathrm{Er}^{3+}$ into $\mathrm{Cs}_{2} \mathrm{AgInCl}_{6} \mathrm{NCs}$, with emission at 996 and $1537 \mathrm{~nm}$ corresponding to the ${ }^{2} \mathrm{~F}_{5 / 2} \rightarrow{ }^{2} \mathrm{~F}_{7 / 2}$ and ${ }^{4} \mathrm{I}_{13 / 2} \rightarrow{ }^{4} \mathrm{I}_{15 / 2}$ transitions, respectively ${ }^{29}$. Unfortunately, the PL QYs for both dopants in $\mathrm{Cs}_{2} \mathrm{~A}$ $\mathrm{gInCl}_{6} \mathrm{NCs}$ are low $(<4 \%)$. Codoping of $\mathrm{Yb}^{3+}$ and $\mathrm{Er}^{3+}$ together into $\mathrm{Cs}_{2} \mathrm{AgInCl}_{6} \mathrm{NCs}$ leads to both dopant emissions (see Fig. 5f), but again with poor $(<1 \%)$ PL QY. $\mathrm{Yb}^{3+}$ doping (and codoping with $\mathrm{Mn}^{2+}$ ions) has also been achieved in $\mathrm{Cs}_{2} \mathrm{AgBiX}_{6}(\mathrm{X}=\mathrm{Cl}, \mathrm{Br}) \mathrm{NCs}$ with an indirect band gap, but the PL QY has not been reported ${ }^{59}$. Better synthesis protocols reducing the nonradiative decay channels are desired to upgrade the optical and optoelectronic properties of lanthanide-doped metal halide double perovskite NCs.

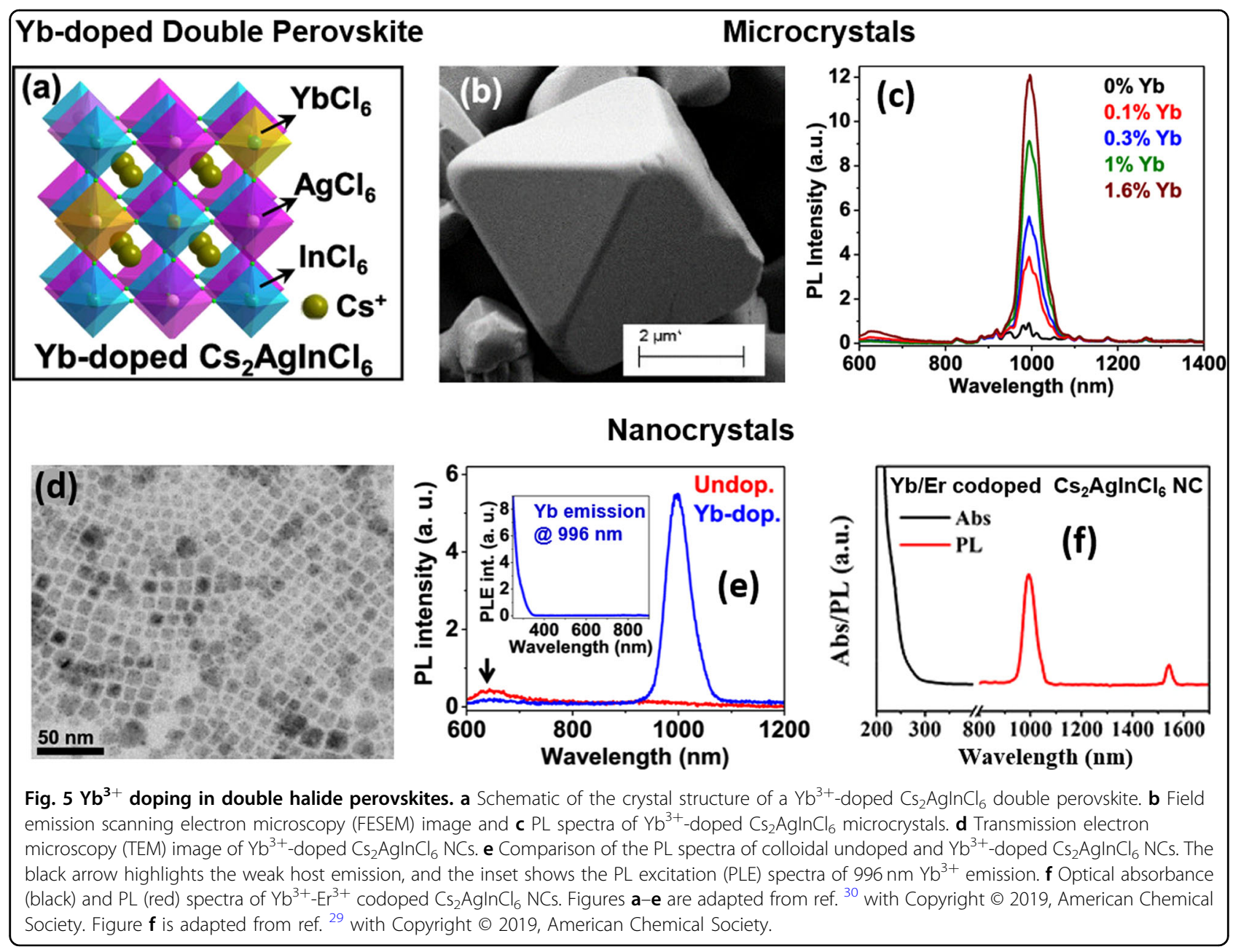




\section{Conclusions and future outlook}

Unlike the poor doping tendency of $\mathrm{Ln}^{3+}$ ions into traditional (CdSe, InP, etc.) semiconductor NCs, doping of $\mathrm{Ln}^{3+}$ into $\mathrm{CsPbX}_{3} \mathrm{NCs}$ that provide the desired octahedral coordination environment is relatively easy. Consequently, in less than three years, $\mathrm{Ln}^{3+}$-doped metal halide perovskite NCs emerged as new visible light harvesting phosphors. Different $\mathrm{Ln}^{3+}$ ions emit light with a well-defined sharp spectral linewidth in the visible and NIR regions, including white light emission obtained by codoping different metal ions. The most important finding thus far is the efficient quantum cutting phenomena in $\mathrm{NCs}$ and thin films of $\mathrm{Yb}^{3+}$-doped $\mathrm{CsPb}(\mathrm{Cl} / \mathrm{Br})_{3}$ perovskites resulting in an extraordinary PL QY approaching $200 \%$. The $\mathrm{Yb}^{3+}$ emission at $\sim 990 \mathrm{~nm}$ can be absorbed by a Si solar cell, and such perovskites are therefore being explored as both (i) a quantum cutting layer on top of a commercial silicon solar cell and (ii) an LSC. In a different direction, $\mathrm{Ln}^{3+}$ doping can also improve the quality and stability of perovskite crystals, improving the performance of perovskite solar cells. $\mathrm{Yb}^{3+}$ and $\mathrm{Er}^{3+}$ have also been doped into $\mathrm{Pb}$-free double perovskite $\mathrm{NCs}$, but with poor PL QY.

There are many new opportunities and challenges that need to be addressed in the future. $\mathrm{Ln}^{3+}$ ions give rise to a strong magnetic moment per free ion, which includes both orbital and spin contributions. For example, Dy ${ }^{3+}$ and $\mathrm{Ho}^{3+}$ with 5 and 4 unpaired electrons can generate a magnetic moment of $>10 \mu_{\mathrm{B}}$ per ion. Such spin-based properties, including magneto-optical properties, have not yet been explored for lanthanide-doped perovskite NCs.

Another promising direction is to fabricate highefficiency NIR LEDs and sensors. Extending the existing knowledge of device physics for undoped host $\mathrm{CsPbX}_{3}$ $\mathrm{NCs}$ to $\mathrm{Yb}^{3+}$-doped samples appears to be a natural next step. If an efficient and stable NIR LED can be prepared from solution-processed and low-cost $\mathrm{Yb}^{3+}$-doped $\mathrm{CsPbX}_{3} \mathrm{NCs}$, then it may find commercial applications. Likewise, extending the LSC properties to applications by integrating a photovoltaic module at the edges of an LSC panel will be interesting. However, fine tuning of the host composition to absorb the optimal level of solar light is required.

Additionally, the characterization of the local structure around the dopant ions and their spatial distribution in NCs are not sufficiently studied. The distinction between properties arising from $\mathrm{Ln}^{3+}$ dopants on the surface of $\mathrm{CsPbX}_{3} \mathrm{NCs}$ and those from dopants in the core of NCs needs to be further understood by employing various experimental techniques. Likewise, a microscopic understanding of quantum cutting in $\mathrm{Yb}^{3+}$-doped $\mathrm{CsPCCl}_{3}$ $\mathrm{NCs}$, which is believed to proceed through the formation of a defect complex ( $\left.\mathrm{Yb}-\mathrm{Cl}-\mathrm{V}_{\mathrm{Pb}}-\mathrm{Cl}-\mathrm{Yb}\right)$, also requires further experimental validation. Finally, there are scopes to improve the quality of lanthanide-doped double perovskite $\mathrm{NCs}$ and, in general, lanthanide-doped $\mathrm{Pb}$-free halide perovskites to explore their potential as optoelectronic materials.

\section{Acknowledgements}

This work is supported by the Science \& Engineering Research Board (SERB, EMR/2017/001397), India, Fundamental Research Funds for the Central Universities (D2190980), the Guangdong Provincial Science \& Technology Project (2018A050506004) and National Natural Science Foundation of China (51961145101). T.S. and H.B. acknowledge the University Grants Commission (UGC) India for student fellowships.

\section{Conflict of interest}

The authors declare that they have no conflict of interest.

\section{Publisher's note}

Springer Nature remains neutral with regard to jurisdictional claims in published maps and institutional affiliations.

Received: 18 September 2019 Revised: 16 November 2019 Accepted: 18 November 2019.

Published online: 24 January 2020

\section{References}

1. Xia, Z. \& Meijerink, A. Ce ${ }^{3+}$-doped garnet phosphors: composition modification, luminescence properties and applications. Chem. Soc. Rev. 46, 275-299 (2017).

2. Mahalingam, V., Vetrone, F., Naccache, R., Speghini, A. \& Capobianco, J. A. Colloidal $\mathrm{Tm}^{3+} \mathrm{Mb}^{3+}$-doped $\mathrm{LiYF}_{4}$ nanocrystals: multiple luminescence spanning the UV to NIR regions via low-energy excitation. Adv. Mater. 21, 4025-4028 (2009).

3. Xia, Z. \& Liu, Q. Progress in discovery and structural design of color conversion phosphors for LEDs. Prog. Mater. Sci. 84, 59-117 (2016).

4. Agbo, P. \& Abergel, R. J. Ligand-sensitized lanthanide nanocrystals: merging solid-state photophysics and molecular solution chemistry. Inorg. Chem. 55, 9973-9980 (2016).

5. Moore, E. G., Samuel, A. P. S. \& Raymond, K. N. From antenna to assay: lessons learned in lanthanide luminescence. Acc. Chem. Res. 42, 542-552 (2009).

6. Protesescu, L. et al. Nanocrystals of cesium lead halide perovskites $\left(\mathrm{CsPD}_{3}, \mathrm{X}\right.$ $=\mathrm{Cl}, \mathrm{Br}$, and I): novel optoelectronic materials showing bright emission with wide color gamut. Nano Lett. 15, 3692-3696 (2015).

7. Swarnkar, A. et al. Colloidal $\mathrm{CsPbBr}_{3}$ perovskite nanocrystals: luminescence beyond traditional quantum dots. Angew. Chem. Int. Ed. 54, 15424-15428 (2015).

8. Swarnkar, A. et al. Quantum dot-induced phase stabilization of a-CSPbl perovskite for high-efficiency photovoltaics. Science 354, 92-95 (2016).

9. Mir, W. J., Jagadeeswararao, M., Das, S. \& Nag, A. Colloidal Mn-doped cesium lead halide perovskite nanoplatelets. ACS Energy Lett. 2, 537-543 (2017).

10. Morozov, Y. V., Zhang, S., Brennan, M. C., Janko, B. \& Kuno, M. Photoluminescence up-conversion in $\mathrm{CsPBr}_{3}$ nanocrystals. ACS Energy Lett. 2, 2514-2515 (2017)

11. Akkerman, Q. A., Rainò, G., Kovalenko, M. V. \& Manna, L. Genesis, challenges and opportunities for colloidal lead halide perovskite nanocrystals. Nat. Mater. 17, 394-405 (2018).

12. Chiba, T. et al. Anion-exchange red perovskite quantum dots with ammonium iodine salts for highly efficient light-emitting devices. Nat. Photon. 12, 681-687 (2018).

13. Ravi, V. K., Scheidt, R. A., DuBose, J. \& Kamat, P. V. Hierarchical arrays of cesium lead halide perovskite nanocrystals through electrophoretic deposition. J. Am. Chem. Soc. 140, 8887-8894 (2018).

14. Swarnkar, A., Mir, W. J. \& Nag, A. Can B-Site doping or alloying improve thermal- and phase-stability of all-inorganic $\mathrm{CsPbX}_{3}(\mathrm{X}=\mathrm{Cl}, \mathrm{Br}$, I) perovskites? ACS Energy Lett. 3, 286-289 (2018).

15. Das, A. S., Guria, A. K. \& Pradhan, N. Insights of doping and the photoluminescence properties of $\mathrm{Mn}$-doped perovskite nanocrystals. J. Phys. Chem. Lett. 10, 2250-2257 (2019). 
16. Luo, B. et al. B-site doped lead halide perovskites: synthesis, band engineering, photophysics, and light emission applications. J. Mater. Chem. C 7, 2781-2808 (2019).

17. Yuan, R. et al. Eu ${ }^{3+}$-doped $\left.\mathrm{CsPbBr}_{1.5}\right|_{1.5}$ quantum dots glasses: a strong competitor among red fluorescence solid materials. J. Am. Ceram. Soc. 101, 4927-4932 (2018).

18. Zhou, Y., Chen, J., Bakr, O. M. \& Sun, H.-T. Metal-doped lead halide perovskites: synthesis, properties, and optoelectronic applications. Chem. Mater. 30, 6589-6613 (2018)

19. Mir, W. J., Swarnkar, A. \& Nag, A. Postsynthesis Mn-doping in $\mathrm{CsPb}_{3}$ nanocrystals to stabilize the black perovskite phase. Nanoscale 11, 4278-4286 (2019).

20. Zhou, D. et al. Cerium and ytterbium codoped halide perovskite quantum dots: a novel and efficient downconverter for improving the performance of silicon solar cells. Adv. Mater. 29, 1704149 (2017).

21. Pan, G. et al. Doping lanthanide into perovskite nanocrystals: highly improved and expanded optical properties. Nano Lett. 17, 8005-8011 (2017).

22. Milstein, T. J., Kroupa, D. M. \& Gamelin, D. R. Picosecond quantum cutting generates photoluminescence quantum yields over 100\% in ytterbium-doped $\mathrm{CsPbCl}_{3}$ nanocrystals. Nano Lett. 18, 3792-3799 (2018).

23. Mir, W. J. et al. Postsynthesis doping of $\mathrm{Mn}$ and $\mathrm{Yb}$ into $\mathrm{CsPbX}_{3}(\mathrm{X}=\mathrm{Cl}, \mathrm{Br}$, or I) perovskite nanocrystals for downconversion emission. Chem. Mater. 30 8170-8178 (2018).

24. Wegh, R. T., Donker, H., Oskam, K. D. \& Meijerink, A. Visible quantum cutting in $\mathrm{LiGdF}_{4}: \mathrm{Eu}^{3+}$ through downconversion. Science 283, 663-666 (1999).

25. Wang, L. \& Li, Y. Controlled synthesis and luminescence of lanthanide doped $\mathrm{NaYF}_{4}$ nanocrystals. Chem. Mater. 19, 727-734 (2007).

26. Hudry, D., Howard, I. A., Popescu, R., Gerthsen, D. \& Richards, B. S. Structure-property relationships in lanthanide-doped upconverting nanocrystals: recent advances in understanding core-shell structures. Adv. Mater. 31, 1900623 (2019).

27. Martín-Rodríguez, R., Geitenbeek, R. \& Meijerink, A. Incorporation and luminescence of $\mathrm{Yb}^{3+}$ in CdSe nanocrystals. J. Am. Chem. Soc. 135, 13668-13671 (2013).

28. Creutz, S. E., Fainblat, R., Kim, Y., De Siena, M. C. \& Gamelin, D. R. A selective cation exchange strategy for the synthesis of colloidal $\mathrm{Yb}^{3+}$-doped chalcogenide nanocrystals with strong broadband visible absorption and long-lived near-infrared emission. J. Am. Chem. Soc. 139, 11814-11824 (2017).

29. Lee, W., Hong, S. \& Kim, S. Colloidal synthesis of lead-free silver-indium double-perovskite $\mathrm{Cs}_{2} \mathrm{AgInCl}_{6}$ nanocrystals and their doping with lanthanide ions. J. Phys. Chem. C 123, 2665-2672 (2019).

30. Mahor, Y., Mir, W. J. \& Nag, A. Synthesis and near-infrared emission of Ybdoped $\mathrm{Cs}_{2} \mathrm{AgInCl}_{6}$ double perovskite microcrystals and nanocrystals. J. Phys. Chem. C. 123, 15787-15793 (2019).

31. Li, Q. et al. Excitonic luminescence engineering in tervalent-europium-doped cesium lead halide perovskite nanocrystals and their temperature-dependent energy transfer emission properties. J. Phys. Chem. C 122, 29044-29050 (2018).

32. Yin, J., Ahmed, G. H., Bakr, O. M., Brédas, J.-L. \& Mohammed, O. F. Unlocking the effect of trivalent metal doping in all-inorganic $\mathrm{CSPbBr}_{3}$ perovskite. ACS Energy Lett. 4, 789-795 (2019).

33. Ma, J.-P. et al. Insights into the local structure of dopants, doping efficiency, and luminescence properties of lanthanide-doped $\mathrm{CsPbCl}_{3}$ perovskite nanocrystals. J. Mater. Chem. C 7, 3037-3048 (2019).

34. Kroupa, D. M., Roh, J. Y., Milstein, T. J., Creutz, S. E. \& Gamelin, D. R. quantumcutting ytterbium-doped $\mathrm{CsPb}\left(\mathrm{Cl}_{1-x} \mathrm{Br}_{x}\right)_{3}$ perovskite thin films with photoluminescence quantum yields over 190\%. ACS Energy Lett. 3, 2390-2395 (2018).

35. van der Ende, B. M., Aarts, L. \& Meijerink, A. Near-infrared quantum cutting for photovoltaics. Adv. Mater. 21, 3073-3077 (2009).

36. $\mathrm{Li}, \mathrm{X}$. et al. Mechanism for the extremely efficient sensitization of $\mathrm{Yb}^{3+}$ luminescence in $\mathrm{CsPbCl}_{3}$ nanocrystals. J. Phys. Chem. Lett. 10, 487-492 (2019).
37. Milstein, T. J. et al. Anion exchange and the quantum-cutting energy threshold in ytterbium-doped $\mathrm{CsPb}\left(\mathrm{Cl}_{1-x} \mathrm{Br}_{x}\right)_{3}$ perovskite nanocrystals. Nano Lett. 19 1931-1937 (2019).

38. Duan, J. et al. Lanthanide ions doped $\mathrm{CsPbBr}_{3}$ halides for HTM-free 10.14\%efficiency inorganic perovskite solar cell with an ultrahigh open-circuit voltage of 1.594 V. Adv. Energy Mater. 8, 1802346 (2018).

39. Shockley, W. \& Queisser, H. J. Detailed balance limit of efficiency of P-N junction solar cells. J. Appl. Phys. 32, 510-519 (1961).

40. Crane, M. J., Kroupa, D. M. \& Gamelin, D. R. Detailed-balance analysis of $\mathrm{Yb}^{3+}: \mathrm{CsPb}\left(\mathrm{Cl}_{1-x} \mathrm{Br}_{x}\right)_{3}$ quantum-cutting layers for high-efficiency photovoltaics under real-world conditions. Energy Environ. Sci. 12, 2486-2495 (2019).

41. Luo, X., Ding, T., Liu, X., Liu, Y. \& Wu, K. Quantum-cutting luminescent solar concentrators using ytterbium-doped perovskite nanocrystals. Nano Lett. 19 338-341 (2019).

42. Wu, K., Li, H. \& Klimov, V. I. Tandem luminescent solar concentrators based on engineered quantum dots. Nat. Photon. 12, 105-110 (2018).

43. Zhang, $\mathrm{X}$. et $\mathrm{al} . \mathrm{Yb}^{3+}$ and $\mathrm{Yb}^{3+} / \mathrm{Er}^{3+}$ doping for near-infrared emission and improved stability of $\mathrm{CsPbCl}_{3}$ nanocrystals. J. Mater. Chem. C 6, 10101-10105 (2018).

44. Shi, J. et al. Efficient and stable $\mathrm{CsPb}_{3}$ perovskite quantum dots Enabled by in situ ytterbium doping for photovoltaic applications. J. Mater. Chem. A 7, 20936-20944 (2019).

45. Wang, L. et al. A Eu ${ }^{3+}-\mathrm{Eu}^{2+}$ ion redox shuttle imparts operational durability to Pb-l perovskite solar cells. Science 363, 265-270 (2019).

46. Pan, G. et al. Impurity ions codoped cesium lead halide perovskite nanocrystals with bright white light emission toward ultraviolet-white light-emitting diode. ACS Appl. Mater. Interfaces 10, 39040-39048 (2018).

47. $\mathrm{Li}, \mathrm{B}$. et al. High-efficiency cubic-phased blue-emitting $\mathrm{Ba}_{3} \mathrm{Lu}_{2} \mathrm{~B}_{6} \mathrm{O}_{15}: \mathrm{Ce}^{3+}$ phosphors for ultraviolet-excited white-light-emitting diodes. Opt. Lett. $\mathbf{4 3}$ 5138-5141 (2018)

48. Swarnkar, A., Ravi, V. K. \& Nag, A. Beyond colloidal cesium lead halide perovskite nanocrystals: analogous metal halides and doping. ACS Energy Lett. 2 1089-1098 (2017)

49. Pal, J. et al. Synthesis and optical properties of colloidal $\left.M_{3} B_{2}\right|_{9}(M=C s, R b)$ perovskite nanocrystals. J. Phys. Chem. C 122, 10643-10649 (2018).

50. Pradhan, B. et al. Size tunable cesium antimony chloride perovskite nanowires and nanorods. Chem. Mater. 30, 2135-2142 (2018).

51. $\vee$ Volonakis, G. et al. Lead-free halide double perovskites via heterovalent substitution of noble metals. J. Phys. Chem. Lett. 7, 1254-1259 (2016).

52. Ravi, V. K., Singhal, N. \& Nag, A. Initiation and future prospects of colloidal metal halide double-perovskite nanocrystals: $\mathrm{Cs}_{2} \mathrm{AgBiX}_{6}(X=\mathrm{Cl}, \mathrm{Br}$, I). J. Mater. Chem. A 6, 21666-21675 (2018)

53. K, N. N., Nag, A. Synthesis and luminescence of $\mathrm{Mn}$-doped $\mathrm{Cs}_{2} \mathrm{AgInCl}_{6}$ double perovskites. Chem. Commun. 54, 5205-5208 (2018).

54. Locardi, F. et al. Colloidal synthesis of double perovskite $\mathrm{Cs}_{2} \mathrm{AglnCl}_{6}$ and Mn-doped Cs $\mathrm{AglnCl}_{6}$ nanocrystals. J. Am. Chem. Soc. 140, 12989-12995 (2018).

55. Zhou, J. et al. Manipulation of $\mathrm{Bi}^{3+} / \mathrm{In}^{3+}$ transmutation and $\mathrm{Mn}^{2+}$-doping effect on the structure and optical properties of double perovskite $\mathrm{Cs}_{2} \mathrm{NaBi}_{1}$. ${ }_{x} \ln _{x} \mathrm{Cl}_{6}$. Adv. Opt. Mater. 7, 1801435 (2019).

56. Luo, J. et al. Efficient and stable emission of warm-white light from lead-free halide double perovskites. Nature 563, 541-545 (2018).

57. Liu, Y., Jing, Y., Zhao, J., Liu, Q. \& Xia, Z. Design optimization of lead-free perovskite $\mathrm{Cs}_{2} \mathrm{AgInCl}_{6}: \mathrm{Bi}$ nanocrystals with $11.4 \%$ photoluminescence quantum yield. Chem. Mater. 31, 3333-3339 (2019).

58. Locardi, F. et al. Emissive Bi-doped double perovskite $\mathrm{CS}_{2} \mathrm{Ag}_{1-x} \mathrm{Na}_{x} \mid \mathrm{nCl} \mathrm{C}_{6}$ nanocrystals. ACS Energy Lett. 4, 1976-1982 (2019).

59. Chen, $\mathrm{N}$. et al. $\mathrm{Yb}$ - and $\mathrm{Mn}$-doped lead-free double perovskite $\mathrm{Cs}_{2} \mathrm{AgBi}_{6}(\mathrm{X}=$ $\mathrm{Cl}^{-}, \mathrm{Br}^{-}$) nanocrystals. ACS Appl. Mater. Interfaces 11, 16855-16863 (2019). 